\title{
An immunohistochemical study on the presence of nitric oxide synthase isoforms (nNOS, iNOS, eNOS) in the spinal cord and nodose ganglion of rats receiving ionising gamma radiation to their liver
}

\author{
Osman Yılmaz ${ }^{1 凶}$, Zafer Soygüder ${ }^{1}$, Ömer Faruk Keleş², Turan Yaman², \\ Zabit Yener ${ }^{2}$, Ahmet Uyar ${ }^{3}$, Tahir Çakır ${ }^{4}$ \\ ${ }^{1}$ Department of Anatomy, ${ }^{2}$ Department of Pathology, Faculty of Veterinary Medicine, \\ University of Van Yüzüncü Y11, 65080, Van, Turkey \\ ${ }^{3}$ Department of Pathology, Faculty of Veterinary Medicine, University of Hatay Mustafa Kemal, 31040, Hatay, Turkey \\ ${ }^{4}$ Department of Medical Physics, Faculty of Medicine, University of Van Yüzüncü Y11, 65080, Van, Turkey \\ osman_40_5@hotmail.com
}

Received: March 6, $2020 \quad$ Accepted: August 25, 2020

\begin{abstract}
Introduction: This study determined the presence of nitric oxide synthesis isoforms (nNOS, iNOS, and eNOS) in thoracic spinal cord segments and nodose ganglia of rats with gamma-irradiated livers. Material and Methods: Male rats $(n=32)$ were divided into equal groups A, B, C, and D. In group A, the controls, no radiation was applied, while groups B, C, and D received $10 \mathrm{~Gy}$ of ionising gamma radiation. The rats of group B were euthanized at the end of the first day (d1), those of group C on the second day (d2), and those of group D on the third day (d3). The liver, spinal cord segments, and nodose ganglion tissues were dissected and fixed, and the liver sections were examined histopathologically. The other tissues were observed through a light microscope. Results: Regeneration occurred at the end of $\mathrm{d} 3$ in hepatocytes which were radiation-damaged at the end of $\mathrm{d} 1$ and d2. On d1, some nNOS-positive staining was found in the neuronal cells of laminae I-III of the spinal cord and in neurons of the nodose ganglion, and on $\mathrm{d} 3$, some staining was observed in lamina $\mathrm{X}$ of the spinal cord, while none of note was in the nodose ganglion. Dense iNOS-positive staining was seen on $\mathrm{d} 1$ in the ependymal cells of the spinal cord and in the glial cells of the nodose ganglion, and on $\mathrm{d} 3$, there was still considerable iNOS staining in both tissues. There was clear eNOS-positive staining in the capillary endothelial cells of the spinal cord and light diffuse cytoplasmic staining in the neurons of the nodose ganglion on $\mathrm{d} 1$, and on $\mathrm{d} 3$, intense eNOS-positive staining was visible in several endothelial cells of the spinal cord, while light nuclear staining was recognised in the neurons of the nodose ganglion. Conclusion: The nNOS, iNOS, and eNOS isoforms are activated in the spinal cord and nodose ganglion of rats after ionising radiation insult to the liver.
\end{abstract}

Keywords: rats, ionising radiation, nitric oxide synthesis isoforms, nodose ganglion, spinal cord.

\section{Introduction}

Ionising radiation is defined as high-frequency and high-energy X-rays and gamma rays that produce changes by removing electrons from atoms and molecules in organs, tissues, and cells (14). The basic effect of the ionising radiation is that it causes cell death due to damage of DNA $(15,32)$. However, with the application of ionising radiation, another effect is that free radicals are formed that are necessary for life.
The production and detoxification of free radicals are controlled by a very delicate balance in the body. The organism is not affected as long as the equilibrium is not disturbed between the rates of formation and elimination of these molecules. When this balance is disturbed - if the oxidants are increased or the antioxidants are insufficient - the organism is exposed to oxidative stress. In an ongoing imbalanced condition, the functioning of the cellular metabolism is impaired, and cellular aging, inflammatory damage, 
and tissue damage ensue in many vital organs with resulting molecular destruction, and pain is the consequent response $(13,23)$.

Nitric oxide (NO) is a gas derived from the amino acid L-arginine by the action of the enzyme nitric oxidase. NO is a very reactive molecule, and therefore has a very short half-life. It is an unusual inhibitory neurotransmitter because it does not bind to membrane receptors. NO is a stimulating molecule produced by endothelial cells and neurons in the brain. It may have a function in memory creation, because it is located in the hippocampal formation. In addition, NO is also found in the olfactory system, cerebellum, striatum, cerebral cortex, hypothalamus, mesencephalon, and spinal cord $(24,37)$ and may have a role in the development of ependymal cells (29). NO plays a role in epileptic activity, nociception (as an important determinant (27)), learning and memory, anxiety, depression, stress, eating and drinking behaviour, sexual behaviour, neuroendocrine functions, the modulation of neurotransmitter release, the continuity of the blood-brain barrier, the cardiac rhythm, the regulation of the sleep-wake cycle, apoptosis, differentiation, development, and synaptic plasticity. It is also responsible for the neurotoxicity observed in diseases such as Alzheimer's, Huntington's, and cerebral ischaemia (4).

It is well known that NO is produced by isoforms of nitric oxide synthase (neuronal NOS, inducible NOS, endothelial NOS, and bacterial NOS). In general, nNOS is a neuronal and essential form, iNOS is a form that is distributed throughout the body after suitable stimulation or induction, and eNOS is found in the vascular endothelium (6) located in endothelial cells (2). Recently, bNOS activity has been determined in several bacterial species, including notorious pathogens such as Staphylococcus aureus and Bacillus anthracis (12).

The liver is associated with all of the stimulation in the body, both humoral and neural. The brain is potentially stimulated to respond to the sensory information associated with the metabolic, immune, and other functions of the liver $(5,11,22)$. It can alter these functions through hormonal and neural pathways (31). The neural relationship between the liver and the central nervous system is both vagal sensory (parasympathetic) and spinal sensory (sympathetic). Most of the stimuli transmitted by the vagus nerve are delivered to the nucleus of the solitary tract via the left nodose ganglion and a small part via the right nodose ganglion. Spinal sensory stimuli are transmitted through spinal nerves 7-13 to the thoracic spinal cord. Vagal sensory nerve cell bodies are located in the nodose ganglion (NG), and spinal sensory nerve cells are found in the dorsal root ganglion (DRG) (5).

In this study, we aimed to investigate the NOS isoforms (nNOS, eNOS, and iNOS) immunohistochemically in the spinal cord and nodose ganglion of rats exposed to ionising gamma radiation of the liver.

\section{Material and Methods}

Experimental animals. A total of 32 rats aged 4-5 weeks, with a body weight of 190-210 g were used in the study. The animals were housed at a standard temperature $\left(22 \pm 1{ }^{\circ} \mathrm{C}\right)$, and in a 12-h light-dark cycle environment. They were given drinking water and standard pelleted rat food ad libitum. At the end of the three-day period of the experiment, the study was terminated. Then, the rats were anaesthetised with a combination of ketamine $(50 \mathrm{mg} / \mathrm{kg}$, intra peritoneally) and xylazine $(10 \mathrm{mg} / \mathrm{kg}$, intra peritoneally) and euthanised. Thoracic spinal cord segments (th 7-13) and the nodose ganglia were removed and fixed by immersion for $2 \mathrm{~h}$ in $10 \%$ buffered formalin.

Exposure to radiation. The rats were randomly classified into four groups of eight per group. The radiation groups $(\mathrm{B}, \mathrm{C}$, and $\mathrm{D})$ received $10 \mathrm{~Gy}$ of ionising gamma radiation. The irradiations were performed using a cobalt- 60 teletherapy device. The beam concentration was placed at the appropriate depth for the liver region in the ionising radiation groups. The scheme was as follows:

1) Group A: The control group, to which no ionising gamma radiation was applied;

2) Group B: 10 Gray (Gy) of ionising gamma radiation was applied and the experiment was terminated on the first day;

3) Group C: 10 Gy of ionising gamma radiation was applied and the experiment was terminated on the second day;

4) Group D: 10 Gy of ionising gamma radiation was applied and the experiment was terminated on the third day.

Light microscopic examination. At the end of the dissection and fixation, tissue samples (liver, thoracic spinal cord segments (th 7-13), and the nodose ganglia) were embedded in paraffin blocks and serial sections of $4 \mu \mathrm{m}$ were taken with a microtome and prepared on slides. All the sections were stained with haematoxylin-eosin. Then, the liver sections were examined histopathologically by light microscopy (Nikon Eclipse 80i-DS-RI2, Japan). In the next phase, immunohistochemical staining for nNOS, iNOS, and eNOS was performed in the remaining tissue sections using the immunoperoxidase method. Commercial antibodies were visualised on $4-\mu \mathrm{m}$-thick paraffin sections using an indirect streptavidin/biotin immunoperoxidase kit (Histostain Plus Bulk Kit, Zymed, USA). The thoracic spinal cord segments (th 7-13) and nodose ganglion sections were incubated with primary antibodies (nNOS, ab1376; iNOS, ab15323; eNOS, ab76198; all at 1/100 dilution; all 
Abcam, UK) overnight at $4^{\circ} \mathrm{C}$. Finally, to visualise the reactions, the sections were reacted for 5-15 min with diaminobenzidine. The sections were observed and photographed through the light microscope.

\section{Results}

Histopathological examination. In the control group, a normal histological appearance of the liver was determined (Fig. 1A). On the first day after irradiation, the vesicular structure in the nuclei of hepatocytes was replaced by a grey homogenous mass. Furthermore, it was noted that the nuclei of hepatocytes were smaller and marginally hyperchromatic, while the cytoplasm was paler (Fig. 1B).
On the second day, it was found that these changes had also taken place in the nuclei of the hepatocytes in all regions of the liver lobules, and in addition, partial shrinkage had occurred in these nuclei, and hydropic degeneration was seen in their cytoplasm (Fig. 1C).

On the third day, the second-day changes were less prominent in two cases, but in the remaining cases the nucleus and cytoplasm of hepatocytes had a normal appearance (Fig. 1D). This shows that the regeneration of hepatocytes occurred on the third and later days after the rats' irradiation.

Immunohistochemical examination. The presence and distribution of all forms of NOS were investigated in the spinal cord and nodose ganglion by immunohistochemical staining on the first, second, and third days. Rexed lamination was used to identify the locations of NOS-positive cells in the spinal cord (25).
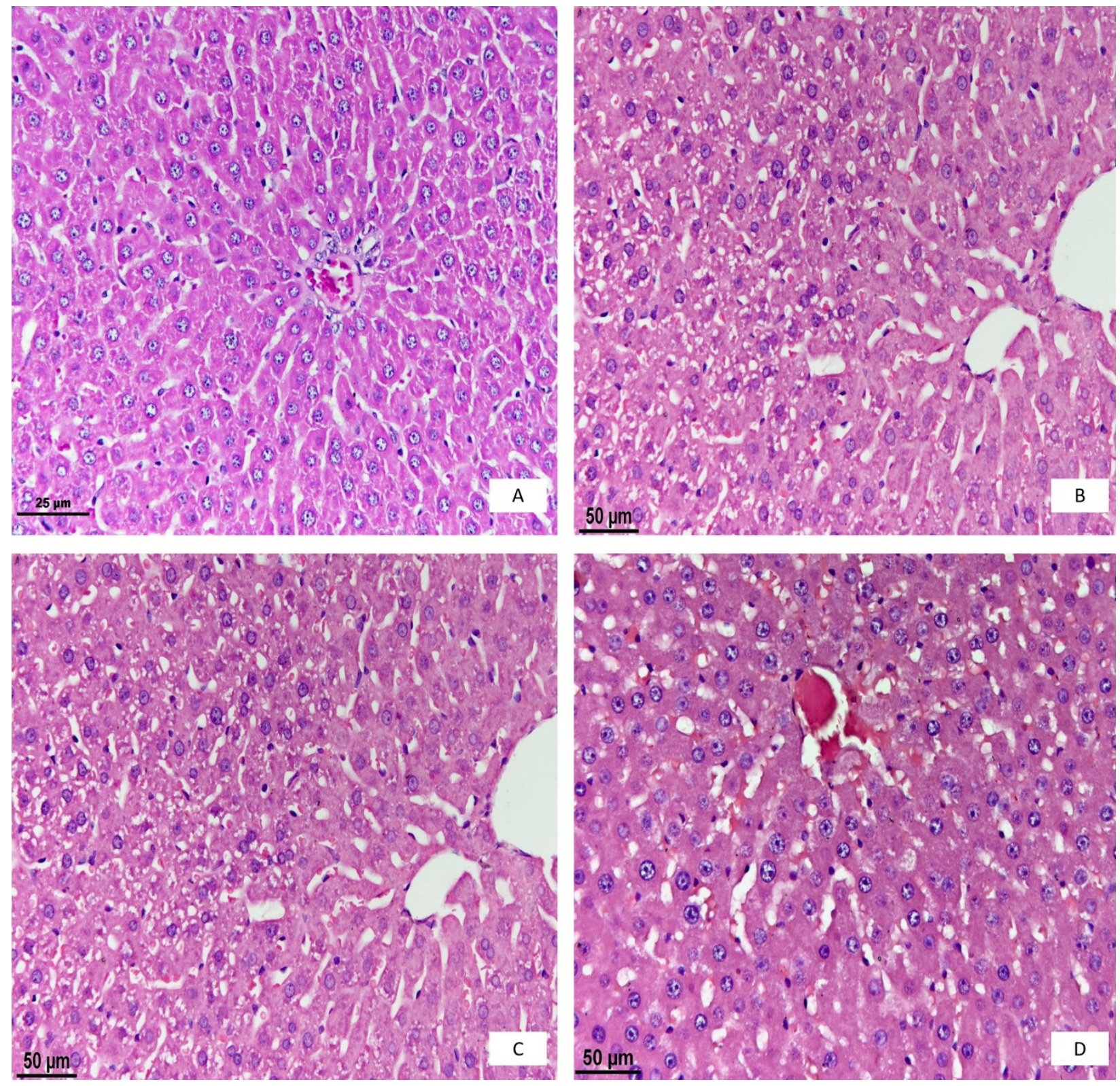

Fig. 1. Histopathological examination of the liver. A - the control group; B - the first day; $\mathrm{C}$ - the second day; D - the third day 
n-NOS immunoreactivity. On the first day, nNOS-positive cells were observed in the superficial lamina (lamina I-II) of the spinal cord of the rats which received ionising radiation to the liver. These cells were also found to a lesser extent in lamina III-IV (Fig. 2A, arrows). In the nodose ganglia, nNOS immunoreactivity was seen as mild perineural staining in several cells (Fig. 2B, arrows).

On the second day, it was seen that nNOS immunoreactivity decreased in lamina I-II to one or two cells (Fig. 2C, arrows). The immunoreactivity of
nNOS in nodose ganglia also decreased and was seen perineurally in one cell (Fig. 2D, arrow).

On the third day, a few nNOS-positive cells were observed in lamina $\mathrm{X}$ of the spinal cord with no remarkable staining in the nodose ganglia (Fig. 2E, F), and nNOS-positivity was detected very mildly in the nucleus of the neurons in the nodose ganglia (Fig. 2F). The immunoreactivity of nNOS, which was present in both tissues on the first day, lessened on the second day, and disappeared on the third day.
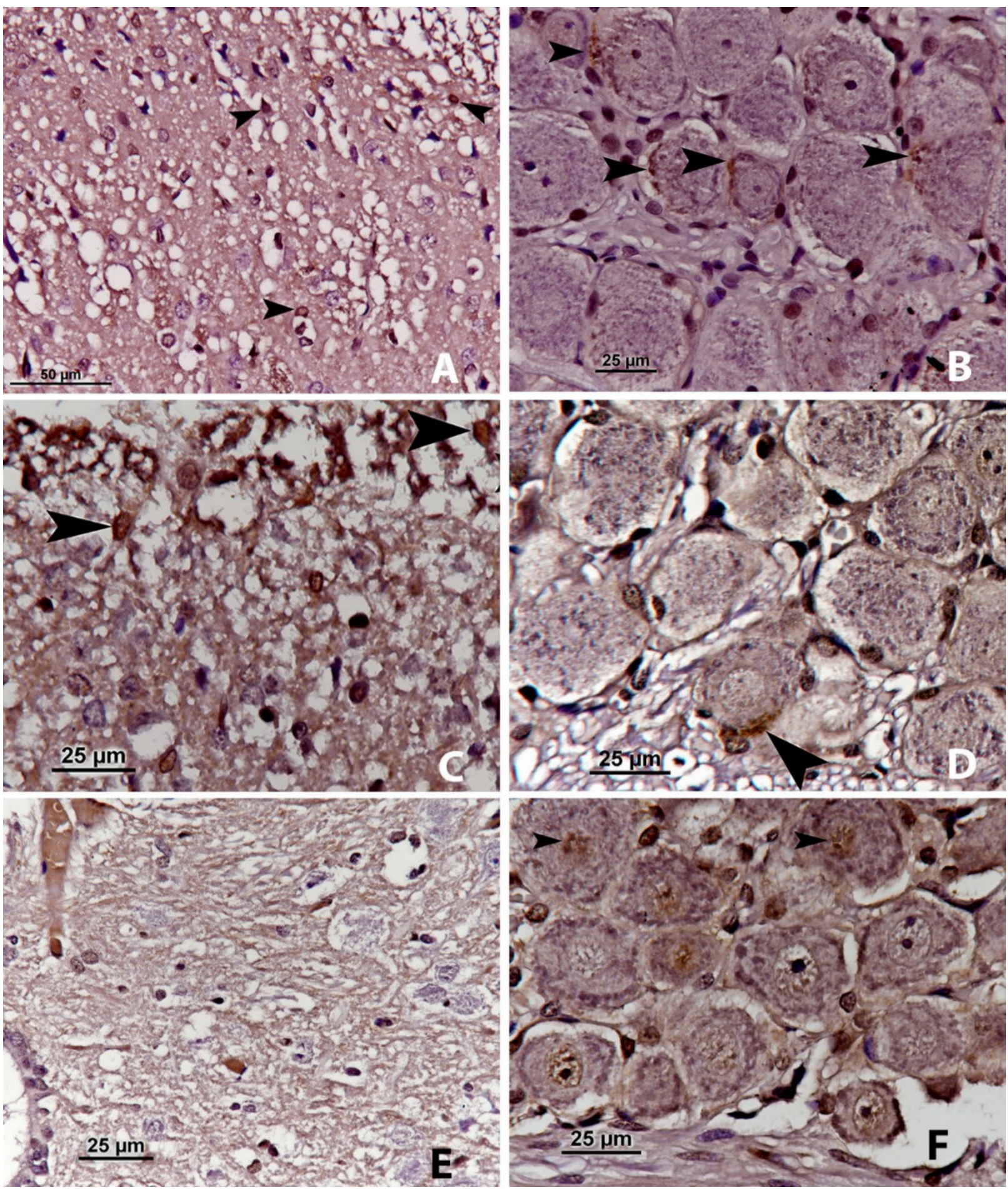

Fig. 2. nNOS immunoreactivity. A - the first day, in the spinal cord; B - the first day, in the nodose ganglion; C - the second day, in the spinal cord; $\mathrm{D}$ - the second day, in the nodose ganglion; $\mathrm{E}$ - the third day, in the spinal cord; $\mathrm{F}$ - the third day, in the nodose ganglion 
iNOS immunoreactivity. On the first day, intensive iNOS immunoreactivity was observed in the ependymal cells around the central canal of the spinal cord. In addition, lamina $\mathrm{X}$ had intense, long axonal staining (Fig. 3A). In the nodose ganglia, iNOS staining was observed commonly as fine granules in the cytoplasm of neurons (Fig. 3B).

On the second day, the immunoreactivity of iNOS was evident with less intensity than on the first day in the ependymal cells of the central canal of the spinal cord. Also, lamina X had weaker and shorter axonal staining than on the first day (Fig. 3C). In the nodose ganglia, iNOS staining was seen as thin granules
(Fig. 3D, thick arrows) in the cytoplasm of neurons, and more prominently in some neuroglial cells (Fig. 3D, arrows).

On the third day, the immunoreactivity of iNOS was determined to be less intense than on the second day in the ependymal cells of the central canal of the spinal cord. The axonal staining in lamina $\mathrm{X}$ was weaker than on the second day (Fig. 3E). This threeday pattern in the spinal cord shows a gradual reduction in iNOS-expression. In the nodose ganglia, iNOS staining was noticed as thin granules in the periphery of the cytoplasm of neurons, and in the neuroglial cells (Fig. 3F).
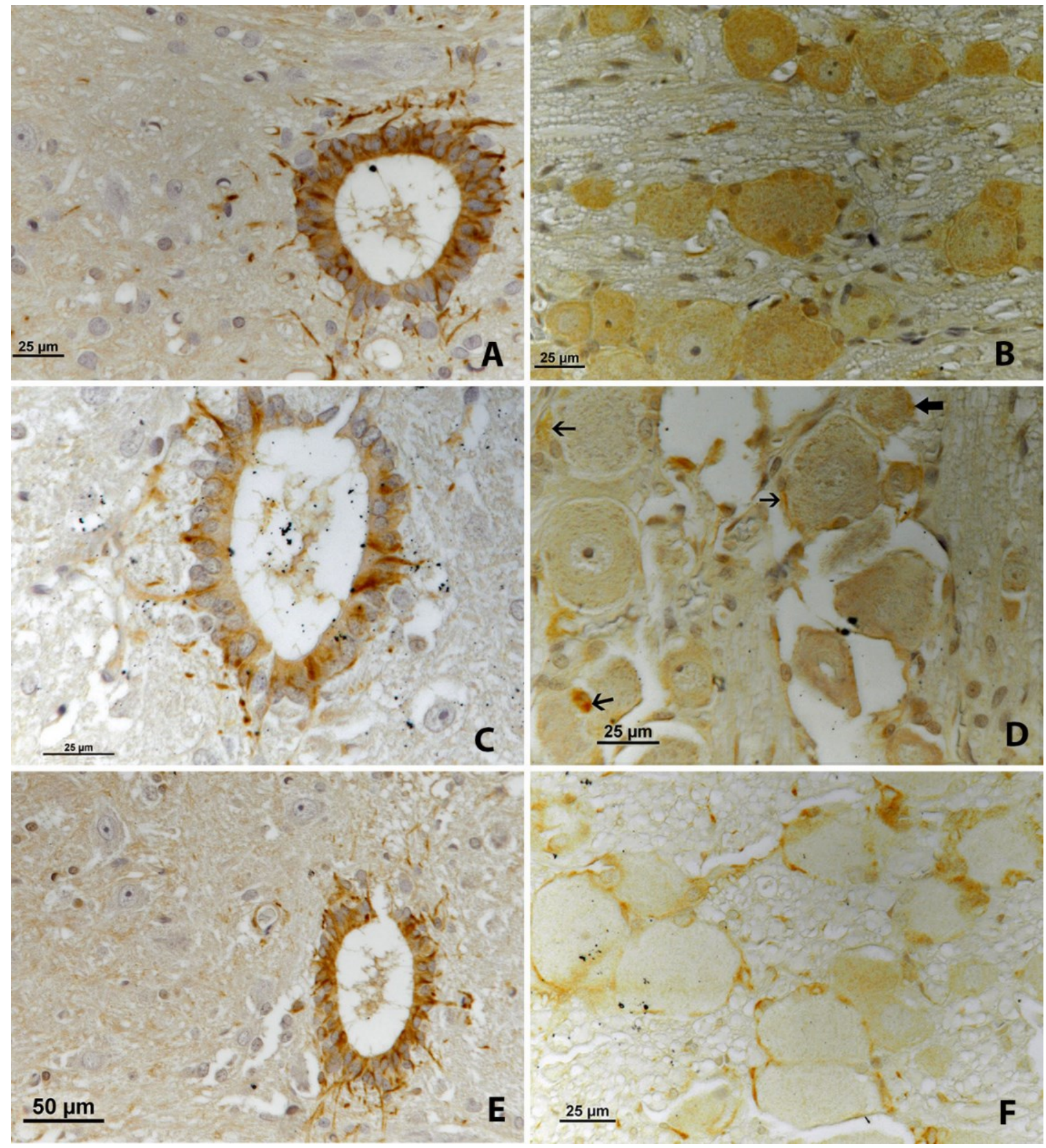

Fig. 3. iNOS immunoreactivity. A - the first day, in the spinal cord; $\mathrm{B}$ - the first day, in the nodose ganglion; $\mathrm{C}-$ the second day, in the spinal cord; D - the second day, in the nodose ganglion; E - the third day, in the spinal cord; F - the third day, in the nodose ganglion 
e-NOS immunoreactivity. On the first day, NOSpositive staining was found in the capillary endothelial cells of the spinal cord (Fig. 4A, arrow). In the nodose ganglia, light diffuse cytoplasmic staining was observed in the neurons (Fig. 4B).

On the second day, light eNOS-positive staining was observed in one or two endothelial cells of the spinal cord (Fig. 4C, arrows). In the nodose ganglion, diffuse cytoplasmic and intense local staining were determined in the neurons (Fig. 4D).

On the third day, intense eNOS-positive staining was visible in several endothelial cells of the spinal cord (Fig. 4E, arrows). A gradual slight increase in eNOS expression in the spinal cord was seen. However, light nuclear staining was observed in the neurons of the nodose ganglia (Fig. 4F).
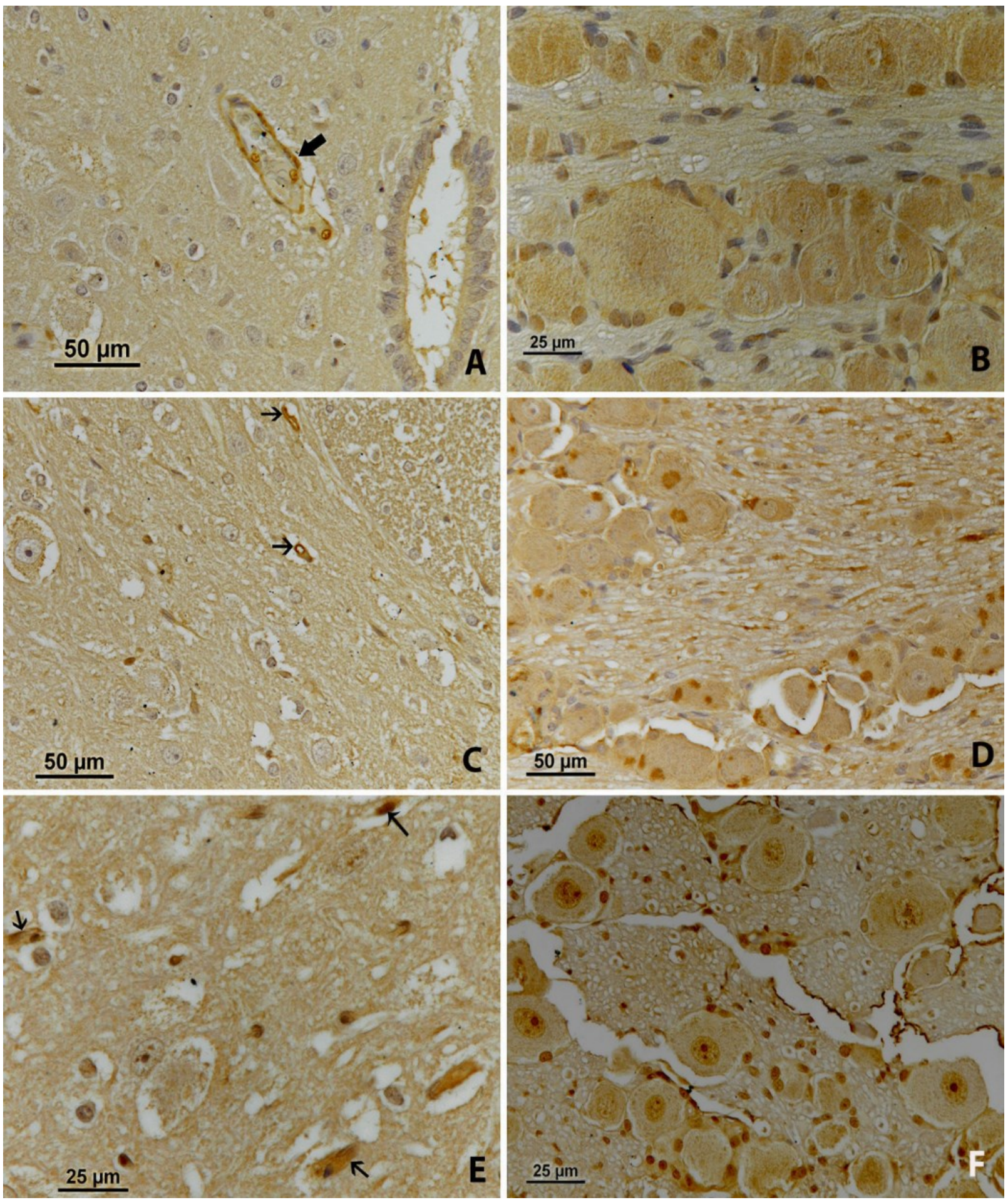

Fig. 4. eNOS immunoreactivity. A - the first day, in the spinal cord; B - the first day, in the nodose ganglion; $\mathrm{C}$ - the second day, in the spinal cord; D - the second day, in the nodose ganglion; $\mathrm{E}$ - the third day, in the spinal cord; F - the third day, in the nodose ganglion 


\section{Discussion}

The basic mechanism of action of ionising radiation results in tissue and various levels of cell damage in many vital organs, such as the liver, and nociceptive pain may be experienced $(13,23)$. NO is an important neurotransmitter substance in nociceptive events of the body (27). The sensory hepatic nerves of the liver - the vagal and spinal afferent innervation of the liver - are well known anatomically, which guides the investigation of the effects of damage to the liver on the nervous system (5).

It has long been known that the mechanism underlying the sense of pain is the release of $\mathrm{NO}$ from the spinal cord $(20,27)$. As an example of the mechanism in effect, nociceptive behaviours have been observed to manifest less in most animal models after intrathecal administration of NOS inhibitors (17, 18, 27). It has been reported that NO is activated as a result of pain following ionising radiation applied to the liver region $(19,32)$. This information supports the data found in our study that demonstrate the immunoreactivity of the NOS isoforms in the spinal cord and the nodose ganglion. However, the present study is the first report that expresses the immunoreactivity of the NOS isoforms in the spinal cord and the nodose ganglion after ionising radiation applied to the liver region where the pain might have occurred.

Although the three forms of NOS (nNOS, iNOS, and eNOS) are all found in the nervous system (1), nNOS predominates in terms of the source of NO in neurons and their localisation in the synaptic area following NO synthase-interacting protein application (9). Normally, nNOS immunoreactivity was confirmed in the dorsal root ganglia $(26,36,38)$, the neurons of the superficial layer of the dorsal horn of the spinal cord, around the central canal, and the neurons of the intermediolateral column cells following noxious peripheral stimulation $(10,30,34,36)$. In addition, nNOS immunoreactivity was observed in some motor neurons of the ventral horn of the spinal cord of rats following induction of chronic arthritis (36). The release of nNOS in the superficial layer of the dorsal horn does not occur during the first few days after birth, and begins to develop in the second week $(16,30$, 36). In the postnatal development phase, its activity was determined in the ependymal cells of the central canal (29). In the present study, the findings for nNOSimmunoreactivities supported those in the cited literature.

In the present study, nNOS immunoreactivity was found in the superficial lamina (lamina I-II) of the spinal cord of the rats with ionising radiation insult to the liver, and to a lesser extent in lamina III-IV. This laminar distribution is consistent with the places where afferent nerve cells activated by noxious visceral stimuli terminate in the spinal cord $(7,8,33)$. Given that nNOS is more likely to be associated with cells in these laminae, it suggests that the presence of nNOS in the spinal cord can be interpreted as being provided through the sensory pathways. We believe that a definitive elucidation could be made with calcitonin gene-related peptide (CGRP)-nNOS double staining. Indeed, c-Fos-nNOS positive double-labelled cells in these laminae were detected as a result of noxious stimuli (28). In the nodose ganglion, nNOS immunoreactivity is seen as mild perineural staining in several cells. The presence of nNOS in both the spinal cord and nodose ganglion suggests that the application of ionising radiation causes noxious stimuli in the liver. The fact that the presence of nNOS in both tissues is high at the beginning, then diminishes, and is not seen at the end, is consistent with the time-dependent decrease reported in the literature $(10,20,26,29,30)$.

Inducible NOS was intensely stained in the ependymal cells of the spinal cord from the first day, and this staining weakened day by day. Ependymal cells are considered a type of neuroglia cell. Considering that among the functions of neuroglia cells is protection of nerve cells (an immune defence function) (35), it can be interpreted that changes in the liver caused by ionising radiation affect the central nervous system, and these radiation stimuli cause increased defence activities in the glial cells. Based on this hypothesis, the dense presence of iNOS in the ependymal cells on the first day and sparser presence on the following days suggests that in the central nervous system in the early days after ionising radiation, NO may have a defensive role in these cells. Dense, granular, focal cytoplasmic staining of iNOS in the nodose ganglia was observed, and the presence of iNOS in these cells is shown for the first time in this study. The synthesis of iNOS results from the stimulation of microbial endotoxins and cytokines (3, 21). In this regard, it is necessary to investigate whether the iNOS-positive neuron cells in the nodose ganglion are activated by the vagal pathway or by the blood circulation.

Endothelial NOS could not be detected in significant presence in the spinal cord. However, from the first day, it was stained in several endothelial cells. In contrast, in the nodose ganglion, mild diffuse cytoplasmic staining in neurons on the first day, intense local cytoplasmic staining on the second day, and nuclear staining on the third day were determined. This eNOS pathway in the spinal cord suggests that NO activated by eNOS may be involved in nuclear regeneration. However, the presence of eNOS in the neurons of the nodose ganglia is observed for the first time. As there are not enough studies on this subject, further studies should be undertaken to clarify what kind of nerve cells the eNOS-positive cells are, or whether these cells are the same as or different from those synthesised by the other isoforms.

In general, the results of this study are consistent with the anatomy of the nerves innervating the liver. They support the data representing the innervation of 
the liver by the spinal and vagal nerves (5). In addition, consideration should be given to the possibility that the immunoreactivity of the irradiation-induced NOS isoforms in the spinal cord is via the agency of sensory neurons, due to damage to the skin where the radiation was applied. We think that differentiation could be achieved with CGRP double-labelling in future studies.

To conclude, it was observed that three NOS isoforms (nNOS, iNOS, and eNOS) were activated in the spinal cord and nodose ganglion of rats treated with ionising radiation to the liver, and that this occurred in different cells (neuronal cells, neuroglia cells, and vascular endothelial cells) of the nervous system.

Conflict of Interests Statement: The authors declare that there is no conflict of interests regarding the publication of this article.

Financial Disclosure Statement: This project was supported by the Van Yüzüncü Y1l University Scientific Research Projects Coordination Unit (project code TSA-2016-5402).

Animal Rights Statements: The study was approved by the Van Yüzüncü Y1l University Local Ethics Committee (VAN YUHADYEK, decision no 2016/06).

\section{References}

1. Alderton W.K., Cooper C.E., Knowles R.G.: Nitric oxide synthases: structure, function and inhibition. Biochem J 2001, 357, 593-615.

2. Alexander B.: The role of nitric oxide in hepatic metabolism. Nutrition 1988, 14, 376-390.

3. Alexandrova R., Mileva M., Zvetkova E.: Nitric oxide and cancer. Exp Pathol Parasitol 2001, 4, 13-18.

4. Aricioglu F.: Nitrik oksit ve santral sinir sistemi. Türk Farmakoloji Derneği, Farmakoloji Eğitim Seminerleri Proğramı, Nitrik Oksitin Farmakolojisi, Seminar Abstracts 2005, pp. 19-21.

5. Berthoud H.R.: Anatomy and function of sensory hepatic nerves. Anat Rec A Discov Mol Cell Evol Biol 2004, 280, 827-835.

6. Burette A., Zabel U., Weinberg R.J., Schmidt H.H.H.W., Valtschanoff J.G.: Synaptic localization of nitric oxide synthase and soluble guanylyl cyclase in the hippocampus. J Neurosci 2002, 22, 8961-8970.

7. Chinapen S., Swann J.M., Steinmann J.L., Komisaruk B.R.: Expression of c-Fos protein in lumbosacral spinal cord in response to vaginocervical stimulation in rats. Neurosci Lett 1992, 145, 93-96.

8. DeLeo J.A., Cooms D.W., McCarthy L.E.: Differential c-fos-like protein expression in mechanical versus chemically induced visceral nociception. Mol Brain Res 1991, 11, 167-170.

9. Dreyer J., Schleicher M., Tappe A., Schilling K., Kuner T., Kusumawidijaja G., Muller-Esterl W., Oess S., Kuner R.: Nitric oxide synthase (NOS)-interacting protein interacts with neuronal NOS and regulates its distribution and activity. J Neurosci 2004, 24, 10454-10465.

10. Dun N.J., Dun S.L., Wu S.Y., Forstmann U., Schmidt H.H.H.W., Tseng L.F.: Nitric oxide synthase immunoreactivity in the rat, mouse, cat, and squirrel monkey spinal cord. Neuroscience 1993, $54,845-857$.

11. Goehler L.E., Gaykema R.P., Hansen M.K., Anderson K., Maier S.F., Watkins L.R.: Vagal immune-to-brain communication: a visceral chemosensory pathway. Auton Neurosci 2000, 85, 49-59.

12. Gusarov I., Starodubtseva M., Wang Z.Q., McQuade L., Lippard S.J., Stuehr D.J., Nudler E.: Bacterial nitric-oxide synthases operate without a dedicated redox partner. J Biol Chem 2008, 283, 13140-13147, doi: 10.1074/jbc.M710178200.

13. Halliwell B.: Free radicals and antioxidants: A personal view. Nutr Rev 1994, 52, 253-265.

14. Hendee W.R., Edwards F.M.: Health effects of exposure to lowlevel ionizing radiation. Acta Radiol 1998, 39, 453-454

15. Karslioğlu I., Ertekin M.V., Taysi S., Koçer I., Sezen O., Gepdiremen A., Koç M., Bakan N.: Radioprotective effects of melatonin on radiation-induced cataract. J Radiat Res 2005, 46, 277-282.

16. Liuzzi F.J., Wu W., Scoville S.A., Schinco F.P.: Development of nitric oxide synthase expression in the superficial dorsal horn of the rat spinal cord. Exp Neurol 1993, 121, 275-278.

17. Mabuchi T., Matsumura S., Okuda-Ashitaka E., Kitano T., Kojima H., Nagano T., Minami T., Ito S.: Attenuation of neuropathic pain by the nociceptin/orphanin FQ antagonist JTC801 is mediated by inhibition of nitric oxide production. Eur $\mathrm{J}$ Neurosci 2003, 17, 1384-1392.

18. Malmberg A.B., Yaksh T.L.: Spinal nitric oxide synthesis inhibition blocks NMDA-induced thermal hyperalgesia and produces antinociception in the formalin test in rats. Pain 1993, 54, 291-300.

19. Mansour H.H., Hafez H.F., Fahmy N.M., Hanafi N.: Protective effect of $\mathrm{N}$-acetylcysteine against radiation induced DNA damage and hepatic toxicity in rats. Biochem Pharmacol 2008, 75, 773-780, doi: 10.1016/j.bcp.2007.09.018.

20. Meller S.T., Gebhart G.F.: Nitric oxide (NO) and nociceptive processing in the spinal cord. Pain 1993, 52, 127-136.

21. Nathan C., Xie Q.: Regulation of biosynthesis of nitric oxide. J Biol Chem 1994, 269, 13725-13728.

22. Obici S., Rossetti L.: Minireview: nutrient sensing and the regulation of insulin action and energy balance. Endocrinology 2003, 144, 5172-5178.

23. Ofluoğlu F.E.: Effects of caffeine on brain L-arginine metabolism in rats. Gazi University, Institute of Health Sciences, PhD Thesis 2007, Ankara, Turkey.

24. Patestas M.A., Gartner L.P.: A Textbook of Neuroanatomy: Neurotransmitter Substances. Blackwell Publishing, Malden, 2006, pp. 44-53.

25. Rexed B.: The cytoarchitectonic organization of the spinal cord in the cat. J Comp Neurol 1952, 96, 415-495.

26. Ruda M.A., Besse D., Inagaki S., DeLeón M., Ren K.: Nitric oxide expression and regulation in the dorsal root ganglion and spinal cord. Ann NY Acad Sci 1994, 738, 181-190.

27. Schmidtko A., Gao W., König P., Heine S., Motterlini R., Ruth P., Schlossmann J., Koesling D., Niederberger E., Tegeder I., Friebe A., Geisslinger G.: cGMP produced by NOsensitive guanylyl cyclase essentially contributes to inflammatory and neuropathic pain by using targets different from cGMP-dependent protein kinase I. J Neurosci 2008, 28, 8568-8576.

28. Soygüder Z.: Mechanisms that are involved in the induction of c-Fos by mustard oil in the rat spinal cord. University of Liverpool PhD Thesis 1996, Liverpool, UK.

29. Soygüder Z., Karadağ H., Nazli M.: Neuronal nitric oxide synthase immunoreactivity in ependymal cells during early postnatal development. J Chem Neuroanat 2004, 27, 3-6.

30. Soygüder Z., Schmidt H.H.H.W., Morris R.: Postnatal development of nitric oxide synthase type 1 expression in the lumbar spinal cord of the rat: a comparison with the induction of c-fos in response to peripheral application of mustard oil. Neurosci Lett 1994, 180, 188-192.

31. Stumpel F., Scholtka B., Jungermann K.: Stimulation by portal insulin of intestinal glucose absorption via hepatoenteral nerves and prostaglandin E2 in the isolated, jointly perfused small intestine and liver of the rat. Ann NY Acad Sci 2000, 915, 111-116. 
32. Taysi S., Koc M., Büyükokuroğlu M.E., Altinkaynak K., Sahin Y.N.: Melatonin reduces lipid peroxidation and nitric oxide during irradiation-induced oxidative injury in the rat liver. J Pineal Res 2003, 34, 173-177. doi: 10.1034/j.1600079x.2003.00024.x.

33. Traub R.J., Pechman P., Iadarola M., Gebhard G.F.: Fos-like proteins in the lumbar spinal cord following noxious and nonnoxious colorectal distention in the rat. Pain 1992, 49, 393-403.

34. Valtschanoff J.G., Weinberg R.J., Rustioni A., Schmidt H.H.H.W.: Nitric oxide synthase and GABA colocalize in lamina II of rat spinal cord. Neurosci Lett 1992, 148, 6-10.

35. Verkhratsky A., Ho M.S., Parpura V.: Evolution of Neuroglia. In: Neuroglia in Neurodegenerative Diseases, Advances in Experimental Medicine and Biology volume
1175, edited by A. Verkhratsky, M. Ho, R. Zorec, V. Parpura. Springer Nature, Singapore, pp 15-44, 2019, doi: 10.1007/978-981-13-9913-8 2.

36. Wu J., Lin Q., Lu Y., Willis W.D., Westlund K.N.: Changes in nitric oxide synthase isoforms in the spinal cord of rat following induction of chronic arthritis. Exp Brain Res 1998, 118, $457-465$.

37. Yilmaz O., Soygüder Z.: Neurotransmitter substances and anatomical localizations. Van Vet J 2017, 28, 177-182.

38. Zhang X., Verge V., Wiesenfeld-Hallin Z., Ju G., Bredt D., Synder S.H., Hökfelt T.: Nitric oxide synthase-like immunoreactivity in lumbar dorsal root ganglia and spinal cord of rat and monkey and effect of peripheral axotomy. J Comp Neurol 1993, 335, 563-575. 